\title{
Liberal Heterosexism: Masculinity, Male Heterosexuality, and the 1969 National Institute of Mental Health Task Force Report on Homosexuality
}

\section{Joseph Lapsley}

The final report of the United States National Institute of Mental Health (NIMH) Task Force on Homosexuality, commissioned in 1967 with Evelyn Hooker as its chair, was originally completed in October 1969. It was only officially published in 1972; the Nixon administration withheld the report as "too liberal and tolerant." Historians have viewed the report in the context of the legacy of Evelyn Hooker, arguably the single most important-revolutionary even-social scientist in gay history. ${ }^{2}$ Their accounts have largely depicted the report as a groundbreaking, positive development-and rightly so. Its policy recommendations to end sodomy laws and discrimination against homosexuals were historic for a major government-sanctioned report. It concluded that homosexuality was a "major problem for our society largely because of the amount of injustice and suffering entailed in it not only for the homosexual but also for those concerned with him."3 Furthermore, as historian Henry L. Minton has observed, "the report challenged the psychiatric orthodoxy of labeling all homosexuals as pathological."

The emphasis on the progressive aspects of the task force's report, however, has obscured the ways in which its authors shared a common ideological vision-a specifically liberal heterosexism-that structured the report's typology of sexual orientations and policy recommendations. Not only did the authors assume the superiority of heterosexuality, the liberal measures they advocated were deliberately aimed at promoting heterosexuality at the expense of homosexuality. With a stated goal of addressing homosexuality in general, the task force's report instead focused almost exclusively on males and masculinity, and was concerned as much, if not more, with male heterosexuality.

The report was liberal in a number of different senses of the word, some of them more apparent than others. For one, it reflected roots in liberal political thought in its focus on what anthropologist Chris Brickell calls the "generic liberal subject," which he argues is "male, White, and heterosexual." Its emphasis on tolerance also revealed assumptions that, according to Brickell, have their basis in a liberal distinction between 'the powerful 'we' who tolerate something with which 'we' do not agree, and a tolerable, less than agreeable 'they,' who are on the receiving end of the tolerator's benevolence."' Perhaps less immediately apparent, the report also revealed elements of liberal economic thought. Its authors shared a vision of a liberal economy analogous to the classical liberal belief in Ricardian and Smithian "free markets," but in this case of sexual-

75

(C) Left History

11.2 (Fall 2006) 
ity rather than economics. They were confident, for example, that the liberalization of sexuality would bring overall positive results, and that lifting restrictions on male sexuality, both heterosexual and homosexual, would allow a kind of invisible sexual hand to foster more and better male heterosexuality and a corresponding reduction in homosexuality. This confidence was tempered, however, by a twentieth century Progressive and New Deal liberal skepticism about the unalloyed good of unfettered markets. They thus envisioned professional, expert assistance in cases of sexual free-market failure. At this point of expert intervention, masculinity played a crucial role as a set of defining characteristics for male heterosexuality. Interventions both at the individual and societal level, they felt, would make masculinity less burdensome. These changes, in turn, would make male heterosexuality more attractive, especially to those who wavered in the realm of bisexual possibility.

The National Institute of Mental Health was founded in 1946 as a part of the National Institute of Health $(\mathrm{NIH})$ under the auspices of the United States Public Health Service. ${ }^{7}$ The NIMH separated from NIH in 1967 (the two reunited in 1992) and could be distinguished from its parent institution by its emphasis on clinical training, mental health services, and the behavioral sciences. ${ }^{8}$ Its early years were marked by optimism about the possibilities for "psycho-social intervention" that focused on the individual in the context of his/her social and cultural environment and community. ${ }^{9}$ The task force's use of sociology and call for society-wide cultural reforms, in this case heterosexuality, and its focus on relieving the suffering of an oppressed minority, i.e. homosexuals, all reflected the larger vision of the NIMH in its first two decades. As Minton explains:

The initiative taken by the NIMH in 1967 to establish a Task Force on Homosexuality reflected the rising tide of the community mental health movement, which had begun in the early 1960s. Within the liberal zeitgeist of the Kennedy and Johnson administrations, federal programs were instituted to promote deinstitutionalization of the mentally ill, community mental health centers, public education, and the special concerns and needs of the poor and oppressed sectors of American society. ${ }^{10}$

This new emphasis drew the analysis of homosexuality away from the post-war psychoanalytic focus on the isolated nuclear triad as the overwhelming determinate of sexual orientation and more towards the impact of culture and society at large.

Evelyn Hooker was a familiar presence at the NIMH by 1967. She had already obtained several research grants and was an acknowledged expert on male homosexuality. She received her first grant from the NIMH to study "nonpatient, nonprisoner homosexuals" in 1953, all of whom were males she con- 
tacted through the Mattachine Society, a primarily male homosexual rights group." Despite knowing women in the lesbian rights group the Daughters of Bilitis (DOB), Hooker was afraid to study women, according to DOB member Billye Talmadge, "because professionally, she would be dead. A woman studying gay women would be highly suspect on any information she presented-it would not have been accepted." 12 While not accounting by any means for the task force report's virtually exclusive focus on males, Hooker's position as a female professional in the $1950 \mathrm{~s}$ and $60 \mathrm{~s}$-combined with the fact that the populations researched under NIMH grants, in general, tended to be overwhelmingly white and male-further skewed the report towards males. ${ }^{13}$

Hooker's views on male homosexuality, however, were unorthodox. She became famous (or infamous, depending on the perspective) as a dissenting voice within the mental health and psychology profession in 1956 when she presented her findings to the American Psychological Association annual meeting in Chicago. In a "packed ballroom" she demonstrated that the most renowned experts in psychological testing could not distinguish between male heterosexuals and homosexuals based on a blind survey of psychological test results. $^{14}$

Hooker's skepticism about the inherent pathology of homosexuality stood in contrast to the far more orthodox position of Stanley F. Yolles, the director of the NIMH. Firmly entrenched in the medical model that pathologized homosexuality, Yolles authored, for example, the introduction to Barbara and Peter Wyden's 1968 Growing Up Straight: What Every Thoughtful Parent Should Know About Homosexuality, a work that uncritically reiterated Irving Bieber's psychoanalytic model of homosexual pathology. According to this model, a "strong" and "emotionally involved" father was a guarantee against a son developing as a homosexual. ${ }^{\text {is }}$ Yolles praised the book as a "valuable service" to parents who wished to "prevent the disorder" in their children. ${ }^{16}$

Despite the differences in their views, Yolles invited Hooker to come to Washington and "tell him what we ought to be doing about homosexuality" in September 1967. Hooker called for an "interdisciplinary group of experts" on homosexuality, and Yolles promised to make appointments for a "blue ribbon task force."17 Hooker envisioned the task force as an impetus to research into sexuality and as a formulator of social and legal policy, both of which added to the controversy surrounding the report. ${ }^{18}$ According to Minton, most of the professionals that Hooker asked to be on the task force "were known for their dissenting views towards psychiatric orthodoxy." 19 From the original total of fifteen task force members, six besides Hooker contributed to the final report and three offered dissenting opinions. Hooker herself wrote the introduction. The authors of NIMH task force report, aside from Hooker, were psychiatrists Judd Marmor and Jerome D. Frank; Paul Gebhard, director of the Institute for Sex Research (the "Kinsey Institute"); professor of religion Robert Katz; professor 
of medicine John Money; and sociologist Edwin Schur. ${ }^{20}$

The task force report broke with the idea that homosexuality was by definition pathological without, however, fully abandoning the medical model. ${ }^{21}$ Its authors assumed that homosexuality was a sub-optimal outcome, and the purpose of the social reforms and therapeutic interventions they recommended was to limit homosexuality as much as they thought possible. The task force report represented an erosion of the medical model that pathologized homosexuality and the emergence of a newer form of heterosexism; its mode of legitimizing male heterosexuality over homosexuality offered a subtler blend of the medical model with elements of cultural heterosexism. As historian Janis Bohan explains, cultural heterosexism "entails the promotion by society in general of heterosexuality as the sole, legitimate expression of sexuality and affection ... [and] includes not only the embedment of this ideology in the explicit teaching of heteronormativity, but also the tacit communication of this ideal via society's norms, institutions, laws, cultural forms, and even scientific practices." ${ }^{\prime 2}$ The ideology of the NIMH report contained elements of the medical model of sexual orientation but also anticipated the other forms of heterosexual supremacy that would only come into vogue in the $1990 \mathrm{~s}^{23}$

Rather than focusing on the 'problem' of homosexuality per se, this newer cultural heterosexism divided society into "good" and "bad" sexual citizens, both homosexual and heterosexual alike. ${ }^{24}$ This mode of heterosexual supremacy would later emerge on a much wider scale in the United States only decades later. It is embodied, sociologist Steven Seidman argues, in the 1993 film Philadelphia, in which "the normal gay is expected to be gender conventional, link sex to love and a marriage-like relationship, [and] defend family values." In this sense the ideology of the NIMH task force report was a forerunner of what Seidman terms the "political logic of tolerance and minority rights that does not challenge heterosexual dominance."2s

The report's ideology also held an assumption much more specific to itself: that if both male hetero- and homosexuality were allowed greater freedom to flourish a more natural competition between the two would result, one less fettered by cultural mores and constraints. Male heterosexuality would gradually outstrip homosexuality to the degree that only "confirmed" or "avowed" male homosexuals would be left as a distinct, but tiny minority. This more "natural" process required assistance, however, and also embedded within this ideology was the assumption that masculinity characterized male heterosexuality. Promoting masculinity amongst males with bisexual potential would assist this less-fettered, natural process of heterosexual success at the expense of homosexuality. They believed, furthermore, that these sexually-malleable males were suitable targets for positive intervention to promote heterosexuality through gender orthopedic efforts to promote masculinity. Thus the task force ideology, through a mix of sexual deregulation and interventionist efforts to 
produce certain kinds of masculinity, especially in the area of bisexual possibility, offered a liberal, tolerant path to heterosexual supremacy. This ideological framework was consistent throughout the report as a whole despite the fact that it contributors came from a variety of professional fields.

Masculinity played a crucial structural role in this ideology because the report authors used characteristics they considered masculine to define male heterosexuality (and in circular fashion, the other way around as well) implicitly against femininity and male homosexuality. This use of masculinity as a set of characteristics for male heterosexuality, while based on common-enough cultural assumptions, also served in the task force report to normatively connect male heterosexuality to male biology.

The task force authors used biology as a teleological, normative ground to bind male heterosexuality to masculinity and to rank it over male homosexuality. This teleological relationship was only open to historical analysis to the degree that male heterosexuality required an explanation for its failure to develop 'correctly' from its origin to its endpoint. In contrast, a 'correct result' did not need to be historically explained, but rather could be accounted for simply by reference to some essential characteristic of its alleged beginning or 'origin.' The authors of the report invoked biology to support their assumption that male heterosexuality/masculinity was a natural phenomenon that, unless interfered with, would be the developmental telos of males. Their use of biology as normative ground stood at odds with their equally-pressing need for a socially-malleable, historically-contingent masculinity that could serve as a site of reform and social research.

The task force's typology of sexual orientations was integral to the ideology that pervaded the report. The content and parameters of male heterosexuality were dependent on what they saw as the characteristics of masculinity, which itself gained its coherence only from its juxtaposition with femininity. They saw male sexual orientations on a hierarchical continuum: male heterosexuality was more valuable than bisexuality, and bisexuality more so than male homosexuality. They viewed boys as the most malleable in terms of masculinity, and thus the best site for gender orthopedic intervention. They also saw this potential plasticity in adult males with bisexual potential, who fell in the middle of their spectrum of sexual orientations. They placed male heterosexuality at the apex of this hierarchical spectrum, defined it by characteristics they categorized as masculine, and assumed that orthopedic efforts to enhance masculinity would improve male heterosexuality's chances relative to homosexuality.

\section{Sexual Deregulation}

The task force report proposed a liberal set of means to attain the same ends as 
those desired by conservatives, i.e. the promotion of heterosexuality and the reduction or elimination of homosexuality. They argued, however, that conservatives' repressive approaches towards sexuality in general were counterproductive. They assumed that there was an optimal set of social conditions, characterized by lower levels of sexual repression and sex segregation, in which male heterosexuality would best flourish at the expense of homosexuality.

The Task Force report authors overwhelmingly shared the view that promoting heterosexuality was better served by tolerant policies towards adult homosexuals rather than repressive efforts, both social and legal. They were thus "strongly convinced," according to the introduction to the final report, "that the extreme opprobrium that our society has attached to homosexual behavior, by way of criminal statutes and restrictive employment practices, has done more social harm than good and goes way beyond what is necessary for the maintenance of public order and human decency."26 Psychiatrist Jerome Frank, a strong proponent of conversion therapy, argued that "it seems probable that both the personal suffering of homosexuals and the social problems they present, could be more effectively combatted [sic] by devoting the same resources to efforts to reduce the social stigma and abolish the legal sanctions to which they are now subjected."27 Sociologist Edwin Shur suggested that reducing legal discrimination against homosexuals would promote heterosexuality by depriving the gay rights movement of a significant organizing point. Legal discrimination against homosexual groups, he felt, drove them to claim homosexuality as non-pathological, and even on par with heterosexuality. Thus he argued that "to the extent that these organizations develop ideologies concerning 'homosexuality as a way of life,' 'the social value of homosexuality,' etc.- - such ideologies should be viewed as having at least partly been 'caused' by current laws and enforcement policies." ${ }^{28}$ From the perspective of these authors, legal restrictions against homosexual sex and social condemnation of homosexuals were contributing to the erosion of heterosexuality and its normatively superior position to homosexuality.

The relaxation of repression against homosexuals, the report's authors argued, should also be accompanied by reducing restrictions on heterosexual activity in society at large. The "perhaps more popular argument," Shur noted, was that "a general 'loosening' of sexual restrictions will necessarily lead to an increase in both heterosexual and homosexual behavior." ${ }^{29}$ Shur instead proposed that "a less restrictive atmosphere regarding heterosexuality in our society might well inhibit the spread of homosexuality." Reducing restrictions on heterosexual activity also played a role in Paul H. Gebhard's analysis. The then-director of the Kinsey Institute remarked that the relatively low "incidence" of male homosexuality in Denmark that one study had found "may be due in large measure to the far greater availability of heterosexual coitus in that culture. ${ }^{30}$ Increased opportunities for heterosexual sex would, according to 
these authors, make homosexual sex less attractive, which was, from their perspective, a positive policy result.

Frank argued that easing restrictions on heterosexuality in society at large could also more specifically benefit therapeutic efforts to convert homosexuals into heterosexuals. Frank lamented the fact that "societal mores" inhibited the use of female prostitutes for the "direct encouragement of heterosexual activity" in conversion therapy efforts. During conversion therapy he explained, "ideally the patient should be shocked in anticipation of or during a homosexual act and reinforced by carrying out heterosexual activity with specially trained prostitutes." He complained, "opportunities for this are, unfortunately, sharply limited by the mores of our society." ${ }^{31}$ Relaxing heterosexual mores in society would not only make homosexuality a less attractive option, they reasoned, but also allow more direct pro-active measures to encourage heterosexuality in therapeutic settings.

The policy recommendations to relax restrictions on heterosexual sex were complemented by John Money's critique of institutional sex segregation as fostering homosexuality. Money claimed that sex segregation as a cultural norm of child-rearing thwarted the promotion of heterosexuality, a retardation that was later reinforced in adolescent and adult same-sex institutions: juvenile detention centers, prisons, and the military. In his contribution to the report, this highly influential professor of Medical Psychology and Pediatrics expressed concern that sex segregation promoted environmentally-influenced homosexuality, which he termed "facultative homosexuality." He hypothesized that "facultative homosexuality in the early years of sexual maturity may be in part a by-product of sexual segregation and cultural injunctions against boy-girl relationships." He noted that "in some societies, indeed, adolescent homosexuality is a prescribed instead of proscribed way of life." His intention, however, was neither to simply describe cultural varieties of sexual attitudes and behavior, nor to relativize sexuality. Rather, he argued that same-sex institutions lay the ground-work for ongoing homosexual behavior into adulthood, and that "after adolescence, facultative homosexuality may be a product of enforced sexual segregation, as in prison or military service." He specifically criticized same-sex juvenile correctional institutions as spaces in which "potentially bisexual people" received "training in bisexuality." The promotion of "facultative homosexuality," he wrote, was "one of the indictments that may be brought against our juvenile detention institutions." 32 Placing males and females together, according to Money, would discourage those who were primarily heterosexual but who had bisexual, or "facultative homosexual" potential, from exercising it. ${ }^{33}$ 


\section{Intervention, Masculinity, and a Hierarchical Typology of Sexual Orientations}

The task force's recommended policy combination of deregulation and intervention, of both non-intervention in sexual behavior and intervention in order to promote male heterosexuality, informed its typology of sexual orientations. Gender served as the key site for this intervention: promoting masculinity amongst males with bisexual potential would ultimately, according to the report, promote male heterosexuality. Unlike gender characteristics, sexual behavior by itself provided little in the way of traits to be actively reformed. Masculinity, however, provided an entire palette of traits, attitudes and dispositions that might be modified. ${ }^{34}$ In their typology, the report's authors distinguished between the extremes of exclusive male heterosexuality and homosexuality, both of which they saw as relatively fixed, and the more malleable middle realm of degrees of bisexuality. The two exclusive endpoints-male heteroand homosexuality - justified their deregulation of sexual behavior, while those in the bisexual middle realm were to be the primary targets of intervention. It was in the middle, bisexual realm, therefore, that the task force focused on masculinity as the defining traits of male heterosexuality. Following the logic that interventions in masculinity could promote male heterosexuality, they focused primarily on categories of people whose sexual orientations appeared less fixed-bisexuals and children.

In the task force report authors' framework, the primary purpose of therapeutic intervention was to achieve shifts within bisexuality towards heterosexual "predominance." The introduction stated that the task force "especially" endorsed therapy for "adolescents and bisexuals" whom they believed to be the most promising candidates. Many adult homosexuals had bisexual capabilities, it continued, and up to half of those "who present themselves for treatment" may become "predominantly heterosexual." Even "about twenty percent" of exclusive homosexuals "could achieve some heterosexual interests and competence if they really wish to do so." Jerome Frank explained, however, that most of the patients who sought treatment were bisexuals and that, in contrast, "exclusive homosexuals seem to seek treatment only for concurrent mental illness, legal difficulties, or inability to stand social pressures. ${ }^{335}$ In delineating a middle range of sexual orientations as the primary area of intervention the report's typology justified the deregulation of the two "exclusive" poles for which, in the promotion of male heterosexuality, intervention and regulation would be counterproductive.

John Money assumed that relative differences in the fixity of sexual orientations could be traced to the degree that they were biologically rooted. $\mathrm{He}$ made a distinction between "obligative homosexuals," whom he saw as relatively fixed in their sexual orientation and for whom he gave biology greater 
explanatory weight, and "facultative" male homosexuals, whom he depicted as more open to environmental influences. ${ }^{36}$ In Money's typology biology played its greatest role at the two extreme ends of his spectrum, with environmental influences at their strongest in the bisexual middle ranges. Money's assumption that biology had a greater role in the "obligative" orientations than in the more bisexual "facultative" ones was consistent with the task force's ideological focus on bisexuality as a primary site of reform and defense against the erosion of male heterosexuality.

Despite the critical role that their typology of sexual orientations played as an organizing framework for their policy recommendations, the report's authors had difficulty clearly distinguishing heterosexuality from homosexuality in terms of personality traits. In the introduction, Hooker's characterization of the overall situation in the United States left the boundaries of 'male heterosexuality' decidedly unclear. She wrote that there were "three or four million adults in the United States who are predominantly homosexual and many more individuals in whose lives homosexual tendencies or behavior play a significant role." ${ }^{37}$ Henry W. Riecken, in a dissenting addendum, pointed out that "there is not even a clearly agreed upon definition of what a homosexual is, what a homosexual act is, or what homosexuality is apart from the rather bland assertion that it is deviant behavior." ${ }^{38}$ This inability to point to clear traits that distinguished one sexual orientation from another-aside from sexual behavior itself-made their project of promoting male heterosexuality more onerous, especially in their targeted area of reform, the 'middle' group of those with bisexual elements. The lack of a set of criteria that marked off the male heterosexual from the homosexual complicated the reforms they were encouraging. They addressed this problem by conflating male heterosexuality with masculinity, which provided a set of traits as the marks of the degree to which a male had heterosexual capabilities.

Unlike male heterosexual and homosexual behavior, for which they promoted relaxations of restrictions, they saw masculinity as a point of policy intervention in the culture. Modifying the norms of masculinity, they believed, could promote male heterosexuality. Both reform thrusts were intended to make male heterosexuality more rewarding and emotionally satisfying and thus a more attractive option in relation to male homosexuality. Reforming masculinity, according to their logic, would do nothing to aid either the confirmed "exclusive" male homosexual or his heterosexual counterpart. It would, they assumed, however, make bisexuality more attractive to males with stronger homosexual tendencies and keep predominantly heterosexual males from exercising any of their own bisexual predilections.

Both Edwin Shur and Judd Marmor linked the erosion of male heterosexuality to what they saw as the demanding and emotionally restrictive nature of masculinity. Shur argued that inflexible or overly-burdensome masculinity was 
partly to blame for a general reduction in "the quality of heterosexual experience." This erosion, "when it results in fear, contempt, or uneasiness, with respect to the opposite sex," he felt, "could play some part in the development of homosexual commitment." He thought that researchers should investigate the "often-remarked difference in tolerance of displays of same-sex affection, etc., in our society-variations according to whether males or females are involved-as this too may relate to relative rates of homosexual orientation." 39 He cited Abram Kardiner's theory that "homosexuality constitutes a 'flight from masculinity' in which the male is overwhelmed by the demanding nature of masculine role-expectations." ${ }^{\circ 0} \mathrm{He}$ also referred to sociologist Edwin Lemert's belief that whatever difficulties were entailed by adopting a homosexual identity it was still a way to avoid burdensome heterosexual roles. "Becoming an admitted homosexual ('coming out') may endanger one's livelihood or his professional career," Lemert observed, "but it also absolves the individual from failure to assume the heavy responsibilities of marriage and parenthood, and it is a ready way of fending off painful involvement in heterosexual affairs." ${ }^{.41}$ Marmor likewise characterized the norms of heterosexual masculinity as so difficult to adhere to that a major characteristic of male homosexuality was flight from heterosexuality. Most male homosexuals, according to Marmor, "seem to be fleeing from the physiological and cultural demands of heterosexuality."A2 Behind Shur and Marmor's analysis lay assumptions that masculinity was integral to male heterosexuality and that a mode of masculinity existed that would maximize male heterosexuality vis-à-vis homosexuality.

The task force report authors' reliance on masculinity to define male heterosexuality was based in two further assumptions: that this cluster of characteristics was normatively bound to male biology and that it was discrete from femininity, which properly belonged to female bodies. The central defining characteristics of masculinity, and hence male heterosexuality, according to the task force authors, were aggression, dominance-seeking, activity (or energy), territoriality, and, in a circular fashion, heterosexual interest itself.

Money included aggression, energy, and participation in male hierarchical struggle among the characteristics of masculinity in young males and directly linked them to male heterosexual development. He contrasted an energetic future male heterosexual, aggressive and concerned about "territorial rights," against a passive future male homosexual, presumably less willing or able to contend for such rights. "In energy expenditure," he wrote, for male heterosexuals "there is quite possibly a difference with regard to aggression and territorial rights, insofar as certain languid, strongly female-identifying homosexual males are persecuted by their age-mates in childhood because they do not fight for a position in the boyhood pecking order." ${ }^{43}$ In Money's understanding, future male homosexuals shared with most girls an unwillingness or inability to fight for dominance within groups of young males, i.e. they lacked masculine 
traits.

Money assumed that a threshold level of "dominance-aggression," which for him was the core characteristic of masculinity, developed after birth, and was required in order for male heterosexuality to develop. Too little aggression in a boy, or to little maternalism in a girl, Money speculated, could contribute to the failure to become a heterosexual. He defined the core gender characteristics as "dominance-aggression" and "maternalism" for masculinity and femininity, respectively. He explained that "lack of dominance-aggression or maternalism, or too much of either, may equally well be conceived of as having a postnatal origin, either in body size, health and strength, or in social contingency learning" (emphasis added). He argued that "atrophic competitive dominance-aggression in a boy, or its hypertrophy in a girl may, dependent on other development experiences, be a contributing influence in the psychosexual differentiation of obligative homosexuality." ${ }^{44}$ For Money, a minimum degree of "dominance-aggression" was essential for the development of male heterosexuality, and served for him as a core of masculinity which was subject to influences after birth, either through physical development/nutritionally, learned behavior, or both.

In his discussion of the therapeutic possibilities for adult homosexuals, Jerome Frank approvingly cited conversion therapists' assertions that characteristics that they defined as masculine were crucial for the development of male heterosexuality. One key trait of masculinity was aggressiveness, the definition of which included "initiation of heterosexual behavior by the patient." ${ }^{\text {"45 }}$ Frank also noted that therapists frequently mentioned "aggressiveness" as a "favorable sign" for successful conversion therapy. On the methods used in group therapy conversion efforts, Frank reported that the purpose of group pressure on the homosexual was to "discard his homosexual mannerisms." Group therapy was supposed to produce a decline in gender mannerisms deemed inappropriate for a male, so that new ones - with a proper fit between biology and behavior-could develop. The benefit of the group approach in promoting this dynamic lay, Frank thought, in the fact that "in groups patients must actively help each other" and thus "the group also combats the homosexual's passivity." "Passivity" in this case was both the antithesis of masculine "activity" and the unwillingness to abandon homosexuality. The therapists thus viewed "masculinity" as evidence for a positive prognosis for converting a male into a heterosexual. Frank reported that "effeminate mannerisms" suggested poor results and that both Irving Bieber and Lawrence Hatterer (both well-known conversion therapy advocates) also associated "passivity" with lack of success in therapy. Hatterer's criteria for success likewise conflated masculinity with male heterosexuality: "the more the patient regards himself as a member of the homosexual community and the patient seeks an unmasculine social and work environment the worse the prognosis. ${ }^{\prime 46}$ At no point in his review of the thera- 
peutic literature did Frank question the fundamental assumption that aggression and a desire for dominance were fundamental characteristics of a masculine gender core that was in turn integral to male heterosexuality.

While the task force authors agreed that aggression was a characteristic of masculinity, and that masculinity was central to male heterosexuality, their contributions to the report reflected utterly opposing perspectives on the relation of aggression to male heterosexuality and the importance of rejecting females as models. Shur, for example, shared Frank's and Money's assumption that the development of masculinity directly related to male heterosexuality, but in contrast to them, Shur was concerned about the role that aggression in boys might play in the formation of male homosexuality. Shur pointed to sociologist Talcott Parsons' idea that when females played the predominant role in childrearing, a particular kind of masculinity developed in young males, characterized by aggression towards women. He cited Parsons theory that boys developed " "compulsive masculinity' against the "sissy' label" once they discover that "women are considered inferior," and how this produces a "shameful identification." "47 Because boys were primarily raised by their mothers, Parsons argued, a "mother fixation" underlay the "neurotic and psychotic disorders of Western men" and led in the latency period to "aggression towards women." This pre-pubescent aggression towards women, Shur argued, should "be relevant to understanding the development of homosexual orientation." ${ }^{\text {" } 8}$ In Shur's discussion, male aggression and the desire not to be a female were, if "compulsive," characteristics that threatened to undermine male heterosexuality. Unlike Shur, Money pointed to the rejection of the "opposite sex pattern," compulsive or otherwise, as critical to male heterosexual development, and both Money and Frank saw aggression as one of the primary characteristics of male heterosexuality. Whatever disagreements about the exact traits that made up "masculinity," the authors assumed that such traits were integral to male biology and characterized male heterosexuality rather than homosexuality. To the degree that readers shared these assumptions, the report would appear to possess greater intellectual cohesion than it really had.

The task force authors saw efforts to mold masculinity amongst boys as particularly important in the prevention of male homosexuality. In the introduction, Hooker argued that an "intensive effort" should be made to understand better how to prevent homosexual orientation from developing in childhood through "effective primary intervention." ${ }^{\text {"49 }}$ John Money explicitly and succinctly connected the "origins" of sexual orientations-heterosexual, bisexual, and homosexual - to gender and childhood. "The primary origins of the three conditions," he explained, "lie in the developmental period of a child's life after birth, particularly during the years of late infancy and early childhood when gender differentiation is being established." He tied the development of masculinity in boys directly to their later heterosexuality and linked the failure to 
develop masculine characteristics to femininity and associated it with the later development of homosexuality. ${ }^{50}$

The historical context of the mid-1960s undoubtedly shaped the nature of the concerns with masculinity and male heterosexuality. In the broadest sense, the Fordist, suburban vision of post WWII America had promoted what historian Robert Corber calls a "domestic" form of masculinity amongst the white middle class that emphasized cooperation and consumption-formerly associated with women - and downplayed competition and aggression.. ${ }^{51}$ For some contemporaries like sociologist Robert Blauner, whose book Alienation and Freedom appeared in 1964, this focus on consumption had led to an increasing sense of meaninglessness, lack of control, and powerlessness at work. Other commentators, however, perceived a very different type of problem with males and masculinity. A 1964 issue of Business Week, for example, described the "type A" personality, which was "aggressive, hard-driving, [and] vigorously competitive." The type A man was prone to heart attacks and other health problems, and likely suffered from loneliness. ${ }^{52}$ The changing roles and increased earning power of women, furthermore, threatened masculine identity. These changes were in part the result of the gradual erosion of the New Deal family wage system that had emphasized white male wage earners. ${ }^{53}$ As sociologist Michael Kimmel argues, in the 1960s the "masculine mystique," that impossible synthesis of sober breadwinner, imperviously stoic master of his fate, and swashbuckling hero, was finally exposed as a fraud." ${ }^{54}$ The various contemporary analyses of the shortcomings of masculinity in the 1960 s rendered a consistent diagnosis difficult. Depending on one's perspective, the culture demanded from males too much emotional expression, sensitivity, and cooperation, or too much aggression and competition. Everyone concerned seemed to agree, however, that there was a problem.

This cross current of ideas about masculinity in US society were reflected in the somewhat contradictory nature of the task force recommendations about which characteristics would best promote heterosexual masculinity. One the one hand, the report's authors recommended therapies to promote masculine aggression and competitiveness to move those with bisexual potential away from homosexuality. On the other hand, they saw male heterosexuality, which they conflated with masculinity, as in need of a general overhaul. If masculinity was made less burdensome then male heterosexuality would better be able to compete against homosexuality. The contradictory impulses within the report, however, did not merely shape the nature of its recommendations. They also reflected intellectual tensions between understandings of sexuality as a social, historical and cultural phenomenon, or as primarily determined by biology.

This tension between 'nature' and 'nurture' manifested itself in a tension between the report's heterosexism and its commitment to viewing sexuality as 
a larger, cultural phenomenon. The task force authors assumed the superiority of male heterosexuality vis-à-vis homosexuality but also argued that homosexuality could not be understood outside the study of heterosexuality. Hooker wrote, "it was the consensus of this Task Force that for the development of a meaningful program it is essential that the study of homosexuality be placed within the context of the study of the broad range of sexuality, both normal and deviant." ${ }^{95}$ The authors did not address why, if both homosexuality and heterosexuality should be targets of investigation, one should be prima facie valued over the other. A prime axis of intellectual inconsistency in the report, therefore, came from the fact that male heterosexuality, for the task force authors, was both a foundational assumption and an object of investigation.

The task force authors insisted that homosexuality should be studied in relation to both heterosexuality and the larger social context. "The taboo on homosexuality has a variety of functions," Hooker argued, "linking it not only with values concerning heterosexual behavior, but also with other aspects of the social system." ${ }^{16}$ Edwin Shur and Paul Gebhard also called for research into the relationships between homosexuality and heterosexuality in ways that invited historical, systemic analysis. For Shur, homosexuality was a "problem" and "not just of individuals; it is a problem of virtually all respects, a problem of the cultures and societies within which it occurs." ${ }^{157}$ Gebhard similarly claimed that "since the context determines the meaning of sexual activity, any serious study of homosexuality must take into account heterosexuality." M8 Marmor argued that to study homosexuality one had to consider the overall contingency of gender, that "gender identifications are closely linked to gender role patterns which vary in different times and in different cultures." ${ }^{\prime 99}$ The task force authors' conclusion that homosexuality could not be understood outside of the study of heterosexuality and society opened heterosexuality to investigation as a culturally, historically contingent phenomenon.

The report treated homosexuality in a contradictory fashion. On the one hand, the report's authors thought it should be viewed alongside with heterosexuality as a social phenomenon. On the other hand, they saw it as a medical condition with an etiology. The implicit acceptance of both perspectives resulted in some striking tensions within the report. In the introduction, for example, Hooker insisted that the "problems of etiology and determinants of homosexuality must be an ultimate concern." Despite the fact that "present evidence is inconclusive," she continued, "it does suggest that homosexuality has multiple etiologic roots." ${ }^{\circ 0}$ At the same time, however, she explicitly challenged the paradigmatic assumption that homosexuality had an etiology at all. She explained, "the continued search for determinants may be more productive if pursued in the perspective of development over time, rather than in the traditional perspective of origins or causes." 61 If homosexuality was the result of "development over time"- an historical process-rather than a medical pathology with deter- 
minant "origins" or "causes," it could not, on that basis, be defined as categorically different from, or inferior to heterosexuality. ${ }^{62}$

The placing of homosexuality in the context of heterosexuality led Edwin Shur to the implicit conclusion that there was no normative distinction between the two, which undermined the basis for his own promotion of male heterosexuality over homosexuality. Shur offered what he called a "scientifically tenable" explanation of homosexuality in relation to heterosexuality. In his view, "the development of a predominantly homosexual orientation represents a deflection of sexual object-choice from the more usual pattern." usual pattern" for Shur was for a person to become a heterosexual unless "deflected" by unspecified intrusions. Shur's statement combined a neutral reference to the fact that heterosexuality was numerically more prevalent with language revealing his teleological assumption of heterosexuality as the natural result of development. Shur's promotion of male heterosexuality at the expense of homosexuality was not based on anything "scientifically tenable," but rather on an assumed teleological relationship between male biology and sexual orientation. Shur's view of male heterosexuality as both a norm to be promoted and an historical phenomenon to be observed was a crystallization of a larger fault line of inconsistency that characterized the entire report. They attempted to address this conflict by directly associating masculinity with male heterosexuality. Masculinity, however, was also a relational phenomenon, dependent on the idea that it had a genuine counterpart in femininity.

John Money explicitly depicted gender behavior as the dichotomous behavior of two sexes, which either develop teleologically, i.e. 'correctly,' or fail to do so. Masculinity and femininity in his understanding were coherent categories, and they complemented each other emotionally and psychologically. They each ultimately 'belonged to' their respective biological sexes. Social learning for Money, for example, was an extension of this basic biological template, in which masculinity was a biological male "sex pattern." In order for masculinity to have coherence and therefore be a target for reform and gender orthopedics, it had to be counter-posed to femininity. In turn, 'masculinity' had to be relevant for the formation of male heterosexuality.

The positing of a causal relationship between gender characteristics and sexual orientation was not merely an unreflective adoption of cultural assumptions by task force members, although that arguably played a role. Their definitions of sexual orientations, rather, were dependent on gender characteristics for their content. In Money's discussion of how biological errors may leave one open to the social learning of "opposite sex behavior patterns," for example, he fused gender and sexual orientation as a "sex pattern." "In the future," he explained, "it may be found that a theory of neural inhibition can be extended to include a faulty postnatal inhibitory mechanism in homosexuals which allow opposite sex behavior patterns, including those built up through social learning, 
to be activated"64 (emphasis added). A biological male should be a heterosexual, according to the task force report ideology, because males should be masculine, and masculinity was in part characterized by heterosexual desire and behavior. Male heterosexuality thus served a dual role in the report as both a normative goal and an object of scientific investigation. The normative view of masculinity and heterosexuality as an expression of male biology stood in tension with the report authors' argument that heterosexuality deserved the same scrutiny as homosexuality. Similarly, they sought to make masculinity normative by anchoring it to male biology, while simultaneously insisting that it was a social phenomenon amenable to reform.

\section{Conclusion}

The authors' ideology shared with conservatives of the period the goal of promoting heterosexuality at the expense of homosexuality but differed considerably concerning the means to achieve that goal. For them male heterosexuality would flourish with a laissez-faire approach to sexuality in general. They shared with conservatives, however, the assumptions that masculinity defined male heterosexuality and that masculinity was a coherent group of characteristics inherently related to male biology, and that it was therefore important to make sure masculinity developed 'correctly.' ${ }^{65}$

Masculinity served as the means by which the task force depicted male heterosexuality as the social expression (barring biological or social irregularities) of male biology. In other words, the task force had no grounds for asserting a male should grow up to be a heterosexual without assuming a normative relationship between male biology and masculinity. They also saw masculinity, however, as a socially malleable, culturally variable phenomenon that required gender-orthopedic guidance in cases were it had not come into full expression, i.e., boys and bisexuals, in order to promote male heterosexuality. The role that masculinity played as a normative phenomenon in this teleological narrative of male heterosexual development clashed, therefore, with their understanding of it as an historically, culturally contingent phenomenon-one amenable to reform. This central intellectual tension within this ideology highlights their dependence on male heterosexuality as an abstract category, which held normative significance only through a purported connection to masculinity. Their definition of masculinity, however, was neither consistent nor coherent, and thus in a circular fashion was dependent on a normative conception of male heterosexuality. As an abstraction, the 'male heterosexual' gave coherence to the idea of a 'natural' sexual orientation that could thus be promoted, according to the task force's ideology, through a combination of relaxing 'artificial' constraints on sexuality and encouraging masculinity, especially amongst males with bisexual tendencies. 
The ideology that frames the 1969-1972 NIMH Task Force Report on Homosexuality was a specific type of liberal heterosexism. It can perhaps be viewed as an intermediate stage in the development of mid- to late-twentieth century heterosexism. In calling for tolerance of some homosexuals while still pushing as many males towards heterosexuality as possible, it stood between the medical model of the early and middle twentieth century's definition of homosexuality as ipso facto a pathology and a late-century cultural heterosexism. The latter made a bourgeois definition of a "sexual good citizen" the standard against which both hetero- and homosexuals should be judged. ${ }^{66}$ The emphasis on an invisible sexual hand to foster more and better male heterosexuality, tempered by a New Deal emphasis on expert compensation for 'freemarket failures' made the report a kind of sexual expression of post-WWII liberalism. The report also reflected the growing uncertainties in the period about how to ground normative claims. In this sense the report was an example of liberal attempts to both be intellectually and scientifically credible and make authoritative assertions with normative import.

The report reflected a liminal position, one that grounded the right to autonomy in biology (for the "obligative" male homosexual), but justified elite intervention on the basis of the socio-cultural contingency of sexuality and gender. In other words, the report tied greater freedom to biological reductionism and greater expert intervention and authoritarianism to a social and historical understanding of human sexual development. This result was arguably a result of the task force's unwillingness to follow the egalitarian implications of its own inability to place heterosexual supremacy on an intellectually credible basis. This same effort at intellectual credibility also helps explain the centrality of masculinity as a set of defining characteristics for male heterosexuality. Because they were liberals, without a sacred book or other authoritarian source to point to, they were left with little other than biology as a normative basis for promoting male heterosexuality through masculinity.

\section{Notes}

1. Homophile Studies, a quarterly sponsored by the homophile group ONE, Incorporated, published the report independently in 1970. Henry L. Minton notes that although there were "reservations about the recommendations on prevention and treatment, homophile leaders applauded the report's overall challenge to the medical model as well as its social policy recommendation." Minton, Departing from Deviance: $A$ History of Homosexual Rights and Emancipatory Science in America (Chicago: University of Chicago Press, 2002), 237.

2. For Hooker's role in gay history see Eric Marcus, Making Gay History: The HalfCentury Fight for Gay and Lesbian Equal Rights (New York: Harper Collins, 2002).

3. [Evelyn Hooker], Introduction to National Institute of Mental Health Task Force on Homosexuality: Final Report and Background Papers, ed., John M. Livingood 
(Rockville MD: US Department of Health, Education and Welfare, National Institute of Mental Health, 1972), 6. For evaluations of the report see Andrew M. Boxer and Joseph M. Carrier, "Evelyn Hooker: A Life Remembered," Journal of Homosexuality, vol. 36, no. 1 (1998): 4-5. Ronald Bayer likewise praises the report for its policy recommendations, lamenting only that it was "by no means critical of therapeutic efforts with homosexuals seeking heterosexual adjustment," which is - to say the least - an understatement. Bayer, Homosexuality and American Psychology: The Politics of Diagnosis (New York: Basic Books, 1981), 53. See also Charles Kaiser, The Gay Metropolis, 1940-1996 (New York: Harcourt, 1997), 123-24.

4. Minton, 237.

5. Chris Brickell, "The Transformation of Heterosexism and its Paradoxes," in Chrys Ingraham, ed., Thinking Straight: The Power, the Promise, and the Paradox of Heterosexuality (New York: Routledge, 2005), 90. On sexual liberalism in the twentieth century and its relationship to homosexuality see John D'Emilio and Estelle Freedman, Intimate Matters: A History of Sexuality in America (New York: Harper \& Row, 1988), 276, 277, 288-297. On the idea that heterosexuality as a non-procreative system undermines white supremacy see Mason Stokes, "White Heterosexuality: A Romance of the Straight Man's Burden," in Ingraham,ed., 131-150.

6. Brickell, 90 .

7. Stanley F. Schneider, "Reflections on Psychology and the National Institute of Mental Health," in Psychology and the National Institute of Mental Health: A Historical Analysis of Science Practice and Policy, eds., Wade E. Pickren and Stanley F. Schneider (Washington DC: American Psychological Association, 2005), 19.

8. Ibid.

9. Rachel. I. Rosner, "'Psychotherapy Research and the National Institute of Mental Health, 1948-1980," in Pickren and Schneider, eds., 117.

10. Minton, 236.

11. Ibid., 227.

12. Marcus, 55.

13. Schneider, 27.

14. Minton, 228.

15. See Irving Bieber, et al., Homosexuality: A Psychoanalytic Study of Male Homosexuals (New York: Basic Books, 1962).

16. Barbara and Peter Wyden, Growing Up Straight: What Every Thoughtful Parent Should Know About Homosexuality (New York: Stein and Day, 1968), 7.

17. Minton, 236.

18. For example, Stanley Yolles, the NIMH director who created the task force and appointed Hooker its chair, was fired upon the report's release and none of its research recommendations were undertaken. Ibid., 236-237.

19. Ibid., 236.

20. The other members who did not write contributions to the report were Edward Auer, psychiatrist; David L. Bazelon, Federal Judge (resigned June 3, 1969); Seward Hiltner, Professor of Theology; Morris Ploscowe, Professor of Law; Stanton Wheeler, Vice President of the Russell Sage Foundation. Clelland Ford and Anthony Wallace, Anthropologists; and Henry Riecken, President of the Social Science Research Council. The dissenters were Ford, Wallace, and Riecken. Ford and Wallace agreed with the pol- 
icy recommendations, but accused the report authors of trying to draw moral conclusions from science. Riecken, unlike Ford and Wallace, disagreed with the policy recommendations to end sodomy laws, etc. NIMH Report, v.

21. The "medical model" of homosexuality in the history of sexuality refers to a variety of qualitative changes from the religious idea of homosexual acts as sin. Some scholars view it as a secularization of the idea of $\sin$, but also as a shift away from a focus on homosexual acts towards a focus on the biology and ontology the homosexual as a type. Bayer, 9. See also for example Jennifer Terry, An American Obsession: Science, Medicine, and Homosexuality in Modern Society (Chicago: University of Chicago Press, 1999), and Thomas Szasz, The Manufacturer of Madness: A Comparative Study of the Inquisition and the Mental Health Movement (New York: Harper \& Row, 1970), 242-259.

22. Janis S. Bohan, Psychology and Sexual Orientation, Coming to Terms (New York: Routledge, 1996), 39.

23. See Steven Seidman, "From Polluted Homosexual to the Normal Gay: Changing Patterns of Sexual Regulation in America," in Ingraham, ed., 39-62.

24. Ibid.

25. Ibid., 45.

26. [Hooker], Introduction to NIMH Report, 6.

27. Jerome Frank, "Treatment of Homosexuals," in NIMH Report, 67. Conversion therapy aimed to convert homosexuals into heterosexuals, it is also known as "reparative therapy." For an intellectual overview of conversion therapy see Jack Drescher, "I'm Your Handyman: A History of Reparative Therapies," Journal of Homosexuality, vol. 36, n. 1 (1998): 19-42.

28. Edwin Shur, "Sociocultural Factors in Homosexual Behavior," in NIMH Report, 40. 29. Ibid., 34.

30. The statistic he referred to was the "the very low (4 percent) incidence among 18 19 year-old Danish draftees reported by Hertoft." Paul H. Gebhard, "Incidence of Overt Homosexuality in the United States and Western Europe," in NIMH Report, 28.

31. He also, however, looked with optimism towards future relaxations of restrictions on heterosexuality since "the work of Masters and Johnson suggests that our cultural mores may be changing sufficiently to make this possible in the not too distant future." Frank, 66 .

32. John Money, "Sexual Dimorphism and Homosexual Gender Identity," Appendix B B 1972, Addendum to NIMH Report, 73. This article first appeared in Psychological Bulletin, vol. 74, no. 6 (1970): 425-440. The table of contents of the NIMH Report lists the title as "Pubertal Hormones and Homosexuality, Bisexuality, and Heterosexuality." 33. Hooker disagreed with Money. She cited psychiatrist Harry Stack Sullivan's theory that emotional same-sex relations, prior to puberty, were essential for (male) heterosexual development. Sullivan explained that heterosexuality required "very close and intense preadolescent friendships with peers of the same sex." He described these samesex relations, Hooker reported, as "one of the essential conditions for heterosexual development." These same-sex pre-pubescent, emotional relations amongst males fostered heterosexuality by preventing "the separation of lust and intimacy "dynamisms." This separation, according to Sullivan, was "one precondition of adult homosexuality." Hooker, "Homosexuality," in NIMH Report, 13. This article was originally published in 
the International Encyclopedia of Social Sciences, ed., David Sills, v. 14 (Crowell, Collier and Macmillan, 1968), 222-223.

34. Sexual behaviors by contrast, for example of the kinds Alfred Kinsey recorded, were physical acts rather than ongoing personality traits.

35. [Hooker], Introduction to NIMH Report, 5. She was quoting Frank: "widely publicizing" these results, Jerome Frank felt, would help "combat the sense of hopelessness, and inevitability so prevalent among homosexuals." See also Frank, 67.

36. Money, 73.

37. [Hooker], Introduction to NIMH Report, 2.

38. Henry W. Riecken, letter to Stanley F. Yolles, NIMH Director, February 12, 1969, "Detailed Reservations Regarding the Task Force Recommendations on Social Policy," Appendix A of NIMH Report, 69.

39. Shur, 34. The increasing unpleasantness of masculinity in American society, therefore, was making male heterosexuality less competitive with male homosexuality. This suggests a scarcity model of sexuality, even a zero-sum model.

40. Ibid. Shur cited Abram Kardiner, "The Flight from Masculinity," in H.M. Ruitenbeek, ed., The Problem of Homosexuality in Modern Society (New York: E.P. Dutton, 1963), 17-39.

41. Ibid.

42. He was contrasting male homosexuals with female homosexuals: "there may be significant numbers of female homosexuals who choose the homosexual route becausefor reasons of unattractiveness, shyness, fears of rejection or lack of available menthey feel shut off from the heterosexual satisfactions they might otherwise prefer." Judd Marmor, "Notes on the Psychodynamic Aspects of Homosexuality," in NIMH Report, 56.

43. While he felt that the gender distinctiveness of the future male sexual orientations was clear enough, he was less certain about the degree to which they were attributable to biology, as he explained that "the relationship of this non-belligerency to the nervous system is still conjectural." Money, 76.

44. Ibid.

45 Frank, 63.

46 Ibid.

47. Parsons saw in this dynamic "the seeds of general patterns of intergroup hostility and aggression in the Western world." Shur, 33.

48. Ibid.

49. [Hooker], Introduction to NIMH Report, 5.

50. Money, 77.

51. Robert J. Corber, Homosexuality in Cold War America: Resistance and the Crisis of Masculinity (Durham: Duke University Press, 1997), 5-7.

52. Blauner and Business Week cited in Michael Kimmel, Manhood in America: A Cultural History (New York: Free Press, 1996), 264-5.

53. See Nancy MacLean, A Postwar Women's History: The 'Second Wave' or the End of the Family Wage?" in A Companion to Post-1945 America, eds., Jean-Christophe Agnew and Roy Rosenzweig (Malden MA: Blackwell Publishers, 2002), 235-259.

54. Kimmel, 262.

55. [Hooker], Introduction to NIMH Report, 3. 
56. Ibid.

57. Shur, 30-31.

58. Gebhard, 26.

59. Marmor, 57.

60. [Hooker], Introduction to NIMH Report, 4.

61. Hooker, "Homosexuality," 14.

62. One reason for their focus on heterosexuality was that the Task Force's ideology was not identical with the medical model of homosexuality, although in places they did overlap. The medical model posited that homosexuality was ipso facto pathological, with the direct implication that it was an appropriate phenomenon for etiological rather than historical explanation. It is possible from the medical model perspective, therefore, to simply label heterosexuality as 'health' and investigate it no further. Ironically, Edwin Shur sharply criticized the medical model for its teleological reasoning. Shur, 30.

63. Ibid., 33.

64. Money, 51.

65. For examples of conservative views in the same period see for example B.L. Smith, "Homosexuality in the Bible and the Law," Christianity Today, 13 (18 July 1969): 7-10; Ralph Gehrke, "The Biblical View of the Sexual Polarity," Concordia Theological Monthly, 41 (April 1970): 195-205.

66. Cultural heterosexism, in a way, revives aspects of the religious/sin model of homosexuality that the medical model supplanted amongst liberals in the mid-twentieth century. Cultural heterosexism shares with its earlier predecessor a focus on the moral superiority of heteronormativity rather than the medical model's emphasis on psycho-pathology, and it once again appears to shift the focus back to the morality of specific sexual acts, rather than on ontological status-whether one 'is' a homosexual or heterosexual. 